\section{Construção e desconstrução das identidades masculinas entre trabalhadores metalúrgicos acometidos de LER/DORT}

\author{
Construction and deconstruction of masculine \\ identities among metalworkers with RSI/WRMD
}

\section{Construcción y deconstrucción de las identidades masculinas entre trabajadores metalúrgicos que sufren LER/DORT}

\section{Resumo}

Este estudo teve por objetivo compreender como trabalhadores metalúrgicos vivenciam a incapacidade prolongada para o trabalho por lesões por esforços repetitivos/distúrbios osteomusculares relacionados ao trabalho (LER/DORT) e o impacto do adoecimento crônico na construção/desconstrução da masculinidade. Foi realizado um estudo qualitativo baseado em entrevistas narrativas com homens metalúrgicos de um complexo automotivo no Estado da Bahia, Brasil. Os resultados revelaram como o conflito da experiência de adoecimento, a tentativa de manutenção da identidade masculina, bem como as expectativas de cumprir as regras ditadas pela masculinidade hegemônica são vivenciadas e significadas no cotidiano. A experiência de adoecimento dos metalúrgicos com LER/DORT se expressa na incapacitação para o trabalho, desconstrução da autoimagem, perda da identidade coletiva, desconstrução do self e interdição do futuro. Conclui-se que a masculinidade hegemônica expõe os homens a mais riscos em saúde, cumpre papel mediador do adoecimento no trabalho, altera trajetórias de cuidado e explica a resistência dos homens em procurar ajuda.

Transtornos Traumáticos Cumulativos; Identidade de Gênero; Masculinidade; Saúde do Trabalhador; Pesquisa Qualitativa
Jorge Henrique Santos Saldanha 1,2 Mônica Angelim Gomes de Lima 3

Robson da Fonseca Neves 4

Jorge Alberto Bernstein Iriart 2

\author{
Correspondência \\ J. H. S. Saldanha \\ Departamento de Fisioterapia, Universidade Federal da Bahia. \\ Av. Reitor Miguel Calmon s/n, Salvador, BA 40110-100, Brasil. \\ jhsaldanha@gmail.com \\ 1 Departamento de Fisioterapia, Universidade Federal da Bahia, \\ Salvador, Brasil. \\ 2 Instituto de Saúde Coletiva, Universidade Federal da Bahia, \\ Salvador, Brasil. \\ 3 Programa de Pós-graduação em Saúde, Ambiente e Trabalho, \\ Universidade Federal da Bahia, Salvador, Brasil. \\ 4 Departamento de Fisioterapia, Universidade Federal da \\ Paraíba, João Pessoa, Brasil.
}




\section{Introdução}

É vasta a literatura que aborda as repercussões das lesões por esforços repetitivos/distúrbios osteomusculares relacionados ao trabalho (LER/DORT) atestando o caráter biopsicossocial desse agravo ${ }^{1}$ cujos estudos epidemiológicos apontam elevados índices de acometimento na população feminina 2.

Poucos estudos, no entanto, abordam a saúde do trabalhador na perspectiva de gênero. A noção de classe trabalhadora homogênea ou de trabalho masculino como universal, presente em muitos trabalhos da área, desconsidera as diferenças de gênero existentes no mundo do trabalho 3,4.

Gênero é um elemento constitutivo de relações sociais baseado nas diferenças percebidas entre os sexos, constituindo-se uma forma primeira de significar as relações de poder 5. A construção social de uma divisão entre os sexos, baseada na naturalização das diferenças, colocando-os como "variantes superiores e inferiores da mesma fisiologia" 6 (p. 24), relaciona o masculino a características ditas positivas da natureza, legitimando o lugar de superioridade do masculino.

Os estudos precursores de Brito 7,8, fundamentados nos conceitos de gênero e divisão sexual do trabalho ${ }^{9}$ para pensar a saúde e o trabalho, argumentam que a saúde das mulheres trabalhadoras é condicionada pela posição que elas ocupam no processo produtivo, pelas diferenças de classe e também por relações de gênero envolvidas.

Os estudos de trabalho e gênero abordam especialmente as condições de trabalho das mulheres, buscando "promover o reconhecimento social e a visibilidade dos trabalhos executados pelas mulheres" 10 (p. 131). É pequena a produção de estudos que abordam a questão do trabalho e a masculinidade. Nesses estudos, a discussão sobre divisão sexual do trabalho se mantém como importante temática, tratando da desigualdade de gênero nas relações de trabalho e buscando compreender o discurso, as escolhas e os comportamentos adotados por homens em situações de trabalho 11,12,13,14.

Apesar do crescente interesse nos estudos sobre saúde do homem, abordando temas como construção do ser masculino e o processo saúde-doença-cuidado, violência, sexualidade e paternidade 15 , ainda é incipiente a articulação de tais temas com a saúde do trabalhador.

Este artigo tem por objetivo explorar as relações entre o adoecimento crônico por LER/DORT em homens metalúrgicos e construção de masculinidades, utilizando as narrativas dos sujeitos sobre suas trajetórias de adoecimento para compreender o impacto da enfermidade crônica em homens e as permanências e transformações no universo masculino por intermédio da experiência da enfermidade.

Parte-se do pressuposto que investigar a experiência de adoecimento crônico em homens acometidos por LER/DORT requer aprofundar a compreensão de como a enfermidade se inter-relaciona com a construção de masculinidade. $\mathrm{O}$ adoecer e o viver com uma doença crônica incapacitante podem gerar conflitos identitários e questionamentos sobre os modelos hegemônicos de masculinidade. As experiências de trabalhadores metalúrgicos com LER/DORT foram tomadas como orientadoras para compreender a produção social da masculinidade no contexto do adoecimento crônico.

O conceito de experiência de adoecimento utilizado neste artigo se apoia na ideia de que experiência da enfermidade é um "termo que se refere aos meios pelos quais os indivíduos e grupos sociais respondem a um dado episódio de doença" 16 (p. 263). Outrossim, explicita como os indivíduos respondem a um episódio de doença atribuindo significados e desenvolvendo modos rotineiros de lidar com a situação.

Connell 17,18 define masculinidade hegemônica como a forma culturalmente idealizada do caráter masculino em um determinado cenário histórico. A masculinidade hegemônica é útil para identificar padrões de atitudes e práticas masculinas que perpetuam a desigualdade de gênero, envolvendo tanto a dominação dos homens sobre as mulheres como o poder de alguns homens sobre outros. Recentemente, Connel \& Messerschmidt 19 atualizaram o conceito de masculinidade hegemônica, mantendo a centralidade da ideia da combinação de pluralidade e hierarquia das masculinidades, mas rejeitando a concepção de um padrão único de poder. Masculinidades 20, no plural, são socialmente construídas e variam em diferentes contextos socioculturais no transcorrer de certo período de tempo, lugares potenciais de identidade e no decorrer da vida de qualquer homem. 


\section{Método}

Para compreender a relação entre adoecimento crônico e construção/desconstrução das masculinidades, optou-se pelo estudo das narrativas enquanto recurso para aproximações interessadas nas dimensões subjetiva e intersubjetiva da experiência, no caso, ser homem, adoecer, ter seu cotidiano modificado e sua identidade de gênero tensionada.

A narrativa é entendida aqui como a forma como os indivíduos expressam, interpretam e comunicam suas experiências de adoecimento. As narrativas permitem, portanto, que os sujeitos coloquem as suas experiências temporalmente, mediadas por ações, eventos e encontros que possibilitam ascender aos significados 21 .

O Centro de Referência em Saúde do Trabalhador do Município de Camaçari, Bahia, Brasil, foi o local escolhido para acessar os informantes desta pesquisa, pois o serviço já possuía vínculo com os trabalhadores, sobretudo pela assistência e reabilitação prestada.

Os participantes foram selecionados pelos seguintes critérios: homens, metalúrgicos do setor automotivo, com diagnóstico de LER/DORT. A escolha dos homens participantes do estudo se deu pela busca nos prontuários de atendimentos da unidade e por indicação dos técnicos do serviço, que auxiliaram no reconhecimento de alguns trabalhadores como bons interlocutores para a pesquisa.

Fizeram parte deste estudo cinco homens que trabalhavam em diferentes fases da produção de automóveis (montagem inicial do chassi, montagem final do veículo, abastecimento da linha de produção e setor de reparos/qualidade). Considerou-se para a estruturação deste artigo a análise da narrativa de um caso central tomado como guia e quatro outros casos cujas narrativas possuem interfaces com as categorias êmicas centrais do estudo. As principais características desses informantes se encontram na Tabela 1.

Para as entrevistas narrativas, procedeu-se às etapas de preparação das entrevistas, iniciação, narração central, fase de perguntas e fala conclusiva em uma adaptação da técnica descrita por Jovchelovitch \& Bauer 22. A pergunta disparadora da proposta foi: "(me) conte sua história, como você se tornou metalúrgico? E nesse trajeto (me) conte sobre seu adoecimento...".

Para a análise, optou-se pela preservação das narrativas no tempo e dos eventos narrados 23 . A análise foi orientada pelas recomendações de Bury 24 que alerta que a história, na análise da entrevista narrativa, é tomada como um todo e situada no contexto da narração. Após a transcrição, o material foi submetido à leitura exaustiva até se criar familiaridade com as histórias narradas. Um resumo das histórias foi produzido, a fim de ajudar a compreensão da descrição feita pelos sujeitos e, posteriormente, uma leitura comparativa permitiu o reconhecimento das semelhanças e diferenças. Em seguida, foi conduzida leitura vertical de cada história buscando estruturas narrativas que fizessem conhecer as trajetórias individuais e identificação de significados atribuídos ao adoecimento e, por fim, a estrutura identitária do ser masculino pós-adoecimento. As narrativas dos cinco homens, que entraram no complexo automotivo em um momento de grandes expectativas de crescimento profissional, compõem o material empírico deste estudo. A leitura horizontal permitiu, porém, adotar como caso-guia a história de Hugo, com a qual as histórias dos demais participantes se conectavam por meio de categorias analíticas pré-definidas e categorias emergentes.

Foram observados os aspectos éticos constantes na Resolução no 466/12 do Conselho Nacional de Saúde. O projeto foi submetido ao Comitê de Ética em Pesquisa da Escola de Enfermagem, Universidade Federal da Bahia, tendo sido aprovado sob o parecer no 182.876. As identidades dos sujeitos foram ocultadas, para isso nomes fictícios foram utilizados.

\section{Resultados e discussão}

Hugo tinha 35 anos, era casado e pai de dois filhos. Começou a trabalhar no complexo automotivo aos 25 anos, na montagem do painel corta-fogo do veículo, retirando da esteira três painéis (com aproximadamente $10 \mathrm{~kg}$ ) por hora, realizando a soldagem do painel no chassi. Após um ano de trabalho, apresentou os primeiros sintomas na região lombar. Trabalhou por mais três meses antes de ser afastado. Permaneceu dois anos e nove meses afastado, retornando ao trabalho em um novo setor da fábrica. Dores nos ombros o levaram a novo afastamento. Em 2008, realizou cirurgia no ombro. 
Tabela 1

Caracterização dos participantes do estudo.

\begin{tabular}{|c|c|c|c|c|c|}
\hline & \multicolumn{5}{|c|}{ Informante (nome fictício) } \\
\hline & Hugo & João & Júlio & Luiz & Ubaldo \\
\hline Idade na entrevista & 35 anos & 40 anos & 53 anos & 35 anos & 39 anos \\
\hline Diagnóstico & $\begin{array}{l}\text { Lesão de ombro } \\
+ \text { transtorno de } \\
\text { discos lombares }\end{array}$ & $\begin{array}{l}\text { Lesão de ombro } \\
\text { + síndrome do } \\
\text { túnel do carpo } \\
\text { + transtorno de } \\
\text { discos cervicais }\end{array}$ & $\begin{array}{l}\text { Lesão de ombro } \\
+ \text { transtorno de } \\
\text { discos lombares }\end{array}$ & $\begin{array}{l}\text { Epicondilite medial } \\
\text { + síndrome do túnel } \\
\text { do carpo + lesão de } \\
\text { ombro }\end{array}$ & $\begin{array}{l}\text { Lesão de ombro } \\
\text { + síndrome do } \\
\text { túnel do carpo } \\
\text { + transtorno de } \\
\text { discos lombares + } \\
\text { contusão de joelho }\end{array}$ \\
\hline $\begin{array}{l}\text { Idade no surgimento da } \\
\text { doença }\end{array}$ & 26 anos & 35 anos & 48 anos & 29 anos & 33 anos \\
\hline $\begin{array}{l}\text { Tempo na empresa no } \\
\text { surgimento da doença }\end{array}$ & 1 ano & 3 anos & 3 anos & 3 anos & 2 anos \\
\hline Tempo atual na empresa & 10 anos & 8 anos & 8 anos & 9 anos & 8 anos \\
\hline $\begin{array}{l}\text { Posição da empresa no } \\
\text { complexo automotivo }\end{array}$ & Empresa principal & Empresa principal & Empresa parceira & Empresa principal & Empresa principal \\
\hline Estado civil & União estável & Casado & Casado & $\begin{array}{l}\text { Divorciado do 1ํ } \\
\text { casamento + união } \\
\text { estável }\end{array}$ & Casado \\
\hline Filhos & Sim & Sim & Sim & Sim & Sim \\
\hline $\begin{array}{l}\text { Situação trabalhista no } \\
\text { momento da pesquisa }\end{array}$ & $\begin{array}{l}\text { Afastado com B91 } \\
\text { * pelo INSS }\end{array}$ & $\begin{array}{l}\text { Afastado sem } \\
\text { benefício }\end{array}$ & $\begin{array}{l}\text { Em retorno ao } \\
\text { trabalho }\end{array}$ & Desempregado & $\begin{array}{c}\text { Afastado com B91 * } \\
\text { pelo INSS }\end{array}$ \\
\hline
\end{tabular}

INSS: Instituto Nacional do Seguro Social.

* B91: benefício de auxílio doença acidentário pago pelo INSS.

Retornou ao trabalho no mesmo ano, permanecendo até 2010. No momento da pesquisa, estava afastado do trabalho, recebendo benefício pela Previdência Social. Durante o período de afastamento do trabalho, Hugo iniciou o curso superior de tecnólogo em logística. Ele conta que antes do adoecimento era um jovem alegre e cheio de amigos, que gostava de sair, ir a festas e praticar esportes. Expressou ter muitos sonhos e planos quando entrou na montadora, pois via a possibilidade de crescer na empresa. Entrou com o propósito de sair do "chão da fábrica" e "subir na empresa" com o passar do tempo. Ele planejava comprar um carro e poupar o dinheiro da participação nos lucros e rendimentos para, no futuro, comprar outra casa ou investir em algum negócio próprio. Atravessando os planos de Hugo surgiram os primeiros sintomas e o diagnóstico de LER/DORT, que o obrigaram a se afastar do trabalho. Com o adoecimento, vieram a redução do salário, a perda de benefícios e o aumento dos gastos com a saúde. Hugo relata que a doença trouxe muitos impactos para sua vida e no que ele entendia ser seu papel de homem dentro da sociedade. Narra que depois do adoecimento se sente "um homem pela metade", pois percebe que não cumpre o que a sociedade espera dele. Para Hugo, "espera-se que um homem tome as rédeas da família, seja de fato o provedor, que faça, corra atrás! Quando surgir um serviço de pintura, quem tem que fazer na casa é o homem da casa. Não se espera que um homem de 29 anos de idade caia na rua [relembra o dia em que não teve forças e caiu no centro da cidade]”. Após o adoecimento, Hugo mostra-se um homem triste, com vida social reduzida, vivendo um conflito entre seus planos e as possibilidades reais. Com a perspectiva de finalização da graduação em logística, Hugo parece vislumbrar um caminho para "mudar de vida", no entanto ainda aguarda o resultado do seu litígio contra a empresa para "seguir em frente".

O adoecimento por LER/DORT representou para Hugo uma ruptura na vida. A constatação de que não pode trabalhar como antes, que não será mais o "trabalhador do mês", reduziu suas chances de ascensão e o levou a abandonar os sonhos traçados ao entrar na empresa. A ruptura também se deu em 
relação aos papéis sociais, visto que a forma como Hugo interpretou e expressou suas experiências de aflição 21 com o adoecimento por LER/DORT foi marcada pela ruptura do projeto de homem operário, em que o corpo masculino, tão importante para a construção e manutenção de uma masculinidade hegemônica, já não correspondia às suas expectativas, assim como as da sociedade para com ele. Esse é o ponto de partida que se toma para discorrer sobre as categorias que marcaram as experiências de Hugo e de outros homens que compartilharam com ele histórias de vida que se tocaram em vários pontos que serão apresentados a seguir.

\section{A experiência de não ser mais o mesmo homem de antes}

"E daí pra cá eu deixei de ser a pessoa. Eles já deixaram de me olhar com os olhos que olhavam antes, que eu era o cara, mas devido às minhas limitações não poderia ser..." (João).

No contexto deste estudo, investigando as histórias de trabalhadores industriais com baixa escolaridade e que vivem na periferia de cidades industriais brasileiras, as principais características determinantes de masculinidade que trazem dilemas para a vida se relacionaram com a impossibilidade de trabalhar, de manter a expectativa de ascensão social, além da impossibilidade de realizar papéis e tarefas ditas masculinas como: o status de provedor, a figura e a autoridade de pai, o uso do corpo em determinadas tarefas na casa, na relação com o esporte e no ato sexual. Esses achados dialogam com as ideias de Bourdieu 6 na medida em que tocam numa certa positividade frustrada dos atos masculinos; além disso, para Connell 17 (p. 189) "vivenciamos as masculinidades (em parte) como tensões musculares, posturas, habilidades físicas, formas de nos movimentar e assim por diante”.

O impacto financeiro é apresentado como significado central do processo de experimentação do adoecimento porque retira desses homens a identidade de provedor, gerando dúvidas e incertezas sobre o cumprimento do papel masculino hegemônico.

"E, sem falar também no setor financeiro, porque cai muito o salário de quem está fora da ativa, afastado com benefício. (...) Tem época que a gente fica sem receber da empresa e sem receber do INSS. E aí, o psicológico da pessoa? A pessoa já está com aqueles problemas todos, ainda vem mais essa situação financeira, aí fica difícil..." (Ubaldo).

Nas classes trabalhadoras, particularmente, o referencial masculino aparece na figura dos mantenedores da casa. Sarti 25, em seu estudo sobre os papéis de homens, mulheres e crianças em famílias pobres, destaca que no projeto de realização de uma família caracterizam-se os papéis de pai de família e mãe/dona de casa e que para a realização desse padrão ideal é necessária a concretização do papel masculino de prover teto e alimento, do qual se orgulham os homens.

A experiência de impedimento ao trabalho é marcante na trajetória de adoecimento. O medo de ser considerado "incapaz", de não conseguir manter a família ou de ser visto como "preguiçoso" ou "vagabundo" marcou a história de Hugo como marca também a de Júlio.

"Quando você vai no INSS é que as coisas ficam complicadas. (...) No meu caso mesmo, eu moro de aluguel. A dona da casa não quer saber. Ai tive que recorrer a minha mãe para tomar dinheiro emprestado. Quer dizer, isso tudo mexe com o sistema nervoso da gente. Porque você fica acuado. (...) Quer dizer, tanto afeta você mentalmente como moralmente..." (Júlio).

Conforme Alves 16, a experiência quando colocada em relevo é capaz de produzir significados. Nesse sentido, Júlio faz referência à moral masculina, constituinte da masculinidade hegemônica, que é ameaçada toda vez que falta dinheiro para honrar os compromissos. O sentimento de fracasso pessoal nas finanças vai se somando a outras experiências negativas que tais homens vivenciam no curso das LER/DORT e são parte fundamental de como eles experimentam o adoecimento crônico. Adoecer para esses sujeitos é, sobretudo, a experiência de questionamento do papel masculino e do estranhamento do modelo de masculinidade dominante, ou seja, de não poder cumprir os papéis e tarefas estabelecidos socialmente do que são "coisas de homem".

Hugo revela como o uso do corpo e a força física são fundamentais para o reforço da identidade masculina associando-se a outros elementos como coragem e dominação. Não ter força para trabalhar, para realizar as atividades de casa e para a socialização constituem experiências negativas no curso do adoecimento. Boltanski 26 (p. 163), analisando o uso instrumental do corpo pelas classes sociais, destaca o fato de que o uso do corpo se subordina às suas funções sociais e, nesse contexto, "a doença se manifestará brutalmente porque não se aperceberam dos sinais precursores ou porque se recusaram a percebê-los”. 
Para os sujeitos ouvidos, a perda das funções do corpo significa a impossibilidade de cumprir papéis de homens trabalhadores, maridos e pais, uma vez que o corpo, para além de um organismo biológico é um instrumento de socialização dos indivíduos, de expressão e representação do eu 26. Walter et al. 27 , discutindo os efeitos do acidente de trabalho entre imigrantes nos Estados Unidos, afirmam que se a identidade masculina desmorona, esses trabalhadores passam a viver uma crise pessoal, já que passam a ter vergonha de ser um homem fraco e deficiente.

Hugo expressa bem o comportamento acima caracterizado pela incapacidade do corpo fora das relações de trabalho porque o seu corpo não mais corresponde ao que ele precisaria para manter o tipo ideal do "faz tudo".

"Eu não posso pintar, não posso fazer um serviço, um reparo na minha casa. E isso é coisa de homem, eu sempre fiz. Lá em casa nunca chamamos um encanador. (...) Eu vou ao mercado e quem empurra o carrinho é minha esposa. (...) Porque eu vejo aquelas mulheres tudo: 'Poxa, a menina magrinha ali, pequenininha, empurrando o carrinho e um jegue desse aí do lado aí, olhando'. Você entendeu?..." (Hugo).

$\mathrm{O}$ acúmulo de situações cotidianas, nas quais o seu corpo falha gerou conflitos internos para Hugo e também na sua relação com os outros. Além disso, moldou a compreensão dele de que possui um corpo incompleto, que teve uma parte de suas funções expropriada, especialmente as funções ligadas à força física. Charmaz 28 afirma que os homens podem experimentar o adoecimento crônico como um inimigo, como um aliado, como uma presença intrusiva ou como uma oportunidade e que geralmente interpretam as doenças como inimigas ou como uma presença intrusa, fato que impinge a eles que passem a duelar com a doença durante longo período, na busca de manter sua identidade passada. Nesse sentido, a doença expõe e denuncia uma virilidade arranhada 6 .

\section{Eu sou um scrap: a experiência de ser sucata, de ter um corpo descartável e incapaz}

"Eu não sei até quando eu vou aguentar não. O serviço é bom, mas se eu estivesse inteiro. Não estou. Eu estou scrapeado como os caras chamam agora. O 'véi' está scrapeado [risos]. E você sabe que scrap não presta para nada. Na gíria lá deles, é, o 'véi' tá scrapeado..." (Júlio).

No "chão da fábrica", os trabalhadores significam o que é ter LER/DORT e o fazem pelo uso de uma metáfora. Scrapear é um termo originado na palavra em inglês scrap (sucata) e é utilizada no setor automotivo em substituição a sucatear ou descartar. Na montadora, materiais que não podem ser utilizados e aproveitados devem ser "scrapeados". Com essa metáfora, Júlio dá vida ao sentimento que está presente em Hugo, João, Ubaldo, Luiz e tantos outros trabalhadores que eram parte da linha de produção, mas adoeceram ao experimentar precárias condições de trabalho na indústria automotiva 29 e foram descartados como sucata.

A experiência de viver com LER/DORT é para esses homens insuportável, pois o seu cotidiano requer que eles façam tudo igual a antes e eles já não podem mais, e por isso são considerados diferentes. Nesse contexto, tratar da sexualidade para homens com LER/DORT não é fácil. Muitas vezes, os entrevistados utilizaram metáforas como "essa situação", "isso aí” para se referir às dificuldades nas atividades sexuais. Para os pesquisadores, o dito foi tão importante quanto o não dito quando se tocou no tema da sexualidade. As expressões faciais, os risos, quando falavam de temas difíceis, demonstraram que esse é um tema com interdições, que os homens têm dificuldade para expor. O diálogo com um pesquisador homem e profissional de saúde facilitou a aproximação desse tema, permitindo estabelecer uma conversa sobre possíveis obstáculos, respeitando os limites dos interlocutores.

Entre as dimensões que constituem a masculinidade, a sexualidade é uma das mais explicitamente cobradas para afirmar o "rito de passagem" que atesta que o rapaz virou um "homem de verdade". O modelo social de dominação masculina determina que o homem é o sujeito ativo da relação, que ele deve tomar as iniciativas, satisfazer as mulheres, ter muitas mulheres e sempre se mostrar forte e viril 6 . Essa normatização é relativizada com o adoecimento. Esses homens passam a precisar da ajuda efetiva das companheiras para realizar o ato sexual, vivenciam conflitos nos relacionamentos e em alguns casos até a separação.

Os aspectos acima denunciam um ethos de que homem precisa ser ativo, não pode ficar passivo enquanto a mulher "faz o trabalho". Ao se tornar passivo, ele se aproxima dos traços do feminino, algo condenável no modelo da masculinidade hegemônica 6,17,18. As dores o incomodam, os problemas na sua vida implicam que fazer sexo seja uma vivência difícil e traumática, sobretudo porque o expõe. O 
medo de não conseguir, de piorar a lesão, de precisar parar por causa das dores ou passar a precisar da mulher no ato sexual acarreta, para os homens, a diminuição da frequência de relações sexuais para preservarem a sua identidade e para não serem confrontados.

Gibson et al. 30, em um estudo com homens com distrofia muscular, revelam que esses homens rejeitam relações amorosas, pois entendem, de forma consciente ou não, que não terão sucesso e, consequentemente, não vivenciar é uma forma de não se submeter às regras da masculinidade hegemônica.

A experiência de Luiz com os impactos das LER/DORT na vida sexual explicita um tema pouco abordado nos estudos de adoecimento crônico e masculinidades. Luiz aponta que o imaginário de que é um "homem fraco" e que "não está dando conta" é um problema vivido por homens que experimentam o adoecimento crônico, uma vez que não conseguir manter o mesmo desempenho sexual é significado como uma ameaça à masculinidade. Revela também o jogo entre múltiplos padrões de masculinidades 20 , hegemônica e subalternas, em que o homem tem medo de se aproximar do feminino e de masculinidades subalternas deslegitimadas.

"A pessoa fica achando que a mulher tá achando que o cara está indo para o outro lado, não está gostando mais da coisa, incomoda muito. (...) Será que eu estou dando conta? Será que ela tá se satisfazendo? E eu sou uma pessoa ciumenta. Eu fico com isso na cabeça, fico achando que vou quebrar a cara lá na frente..." (Luiz).

A experiência de ter um "corpo incapaz" é também vivenciada no abandono de práticas esportivas. A prática do futebol, por exemplo, é carregada de sentidos entre homens trabalhadores brasileiros. João dimensiona essa situação quando expõe o quanto essa impossibilidade reforça a sua percepção de incapacidade perante outros homens, reforçando a noção de que a experiência é intersubjetiva e socialmente compartilhada 16 .

"Eu tinha minha atividade física, joguei muita bola, gostava de jogar bola, mas hoje eu tenho cinco anos que eu não jogo bola. Essa alegria na minha vida eu não tenho mais de poder jogar bola. (...) O médico fala: 'João, você pode jogar bola, não pode ir para final.' Então eu não vou jogar bola, né? Eu sei que isso aí eu perdi..." (João).

Dentre as possibilidades de afirmação de uma masculinidade hegemônica, está o signo de homem competidor 28. Os esportes exacerbam essa dimensão da competição entre os homens, entretanto não se descarta o fato de que também podem ser um espaço de socialização masculina, em que os homens se encontram para se divertir, conversar "papos de homem" e isso também contribui na formação da masculinidade hegemônica. Smith \& Sparkes 31, em um estudo com homens que tiveram trauma espinhal devido à lesão no esporte, apresentam que a incapacidade gerada pela lesão trouxe para esses homens um conflito com a masculinidade dominante no esporte. A situação de incapacidade gera a impossibilidade de responder às exigências de autonomia e virilidade. Os autores sugerem ainda a ideia de que homens que confiam em concepções dominantes de masculinidade são muito mais propensos a internalizarem sentimentos de inadequação em uma situação de incapacidade. O que, no entender dos pesquisadores, pode interferir negativamente nos processos de (re)significação da doença.

\section{Masculinidade e paternidade: rupturas, permanências e ressignificações da experiência de adoecer}

Dentre as múltiplas faces da experiência do adoecimento crônico para homens, uma categoria que se mostrou relevante para Hugo foi a paternidade. A paternidade emergiu como um determinante para que o trabalhador permaneça se expondo ao risco no trabalho, mas também apareceu como uma experiência que é ressignificada no processo de adoecimento. Narrar sobre o próprio sofrimento pode produzir novos significados não só para o adoecimento, mas para a vida e suas relações 24 .

Encontraram-se dilemas relacionados à figura do pai mantenedor, autoridade paterna e referência para os filhos, características típicas da masculinidade hegemônica, todavia também foram encontradas preocupações com o cuidado, temática surgida recentemente no contexto da "nova paternidade", em que se percebe maior participação dos homens no cuidado dos filhos 32 .

A identidade de pai mantenedor leva os homens à escolha de permanecerem no trabalho, mesmo quando sentem que estão adoecendo. A compreensão de que não podem se eximir desse papel contribui para o adoecimento.

"Aí peguei família. E aí, como é que sai mais, sem ter uma formação, sem ter nada? Aí fui forçado, mesmo com os problemas lá [empresa], aí fui empurrando com a barriga. Meu caso está ruim porque eu sou chefe de família..." (Luiz). 
Luiz ajuda a revelar como condições socioeconômicas contribuem na determinação do adoecimento dos homens trabalhadores da montadora. Tomando o conceito de iniquidade em saúde 33 (p. 431) como "diferenças desnecessárias e evitáveis (...) ao mesmo tempo consideradas injustas e indesejáveis", não poder se afastar do trabalho que agrava suas condições de saúde, não ter novas oportunidades de trabalho ou viver com incerteza quanto à assistência previdenciária são situações que explicitam um processo de adoecimento que ocorre mediado por iniquidades em saúde.

Para Hugo, as dificuldades financeiras, as interrupções de salário e a perda de benefícios acentuam o conflito da perda de papéis. Medrado 34 representa a figura do pai com um antigo verso: "Levo papai no bolso e mamãe no coração”. Para o autor, essa concepção de paternidade e maternidade em que o pai é responsável pela manutenção, e a mãe pelo cuidado reafirma o modelo dominante de masculinidade. Nesse contexto, quando os homens perdem a capacidade financeira de mantenedor, vivenciam um abalo no modelo hegemônico de figura paterna, acarretando dificuldades na construção de outras masculinidades que permitam cumprir novos papéis na paternidade.

Hugo revela as dificuldades de compartilhar os problemas que os homens vivenciam no cotidiano. Compreender o isolamento e o "não falar" como estratégias de proteção da identidade é fundamental para abordagem da problemática do adoecimento por LER/DORT em homens. Gibson 30 aponta que os homens com adoecimento crônico tendem à marginalização, mas ainda resistem tentando dar algumas respostas a esse processo. Para a autora: "os homens não conseguem escapar da ordem dominante, mas também não sucumbem totalmente” 34 (p. 515).

Nesta pesquisa percebeu-se a dificuldade de os homens revelarem o que sentiam. Faz parte do Ser masculino, construído e aceito socialmente, não demonstrar emoções ou qualquer fragilidade 6,18 Assim, compreender tal dificuldade que os homens possuem de falar o que sentem é fundamental para pensar medidas preventivas nos locais de trabalho. Além disso, reconhecer que a masculinidade hegemônica influencia o modo como os homens se portam diante das doenças é necessário para repensar o cuidado à saúde dos homens. Contudo, é no curso da desconstrução de uma masculinidade hegemônica que também emerge a possibilidade de experimentação de novas masculinidades. O que está posto para esses homens, trabalhadores, vivendo com LER/DORT é o desafio de reorganização do mundo, da existência, a fim de que não resumam suas vidas ao adoecimento 35. A literatura sobre masculinidades conseguiu consolidar importantes pressupostos sobre como os homens se comportam e como formam sua identidade. A ideia de que existem múltiplas masculinidades 17,18,19,20 suscitou o seguinte questionamento: “como os homens no contexto investigado viam o Ser masculino?". Os resultados ratificam um padrão do esperado para uma masculinidade hegemônica, mas foram achadas situações que apontam para a construção de múltiplas possibilidades de formação dessa masculinidade, especialmente na reconstrução do papel de pai e do cuidado dos homens com os filhos.

Hugo já não conseguia sustentar o papel de pai baseado numa masculinidade hegemônica, então, forjou-se uma nova masculinidade, mediada por uma perspectiva de paternidade que independe de ser o mantenedor financeiro, mas que prima pelos laços de cuidado, que busca o aprimoramento educacional e a abertura do negócio próprio como formas de se manter trabalhando com menor sobrecarga física sem que, com isso, se perceba como fraco ou pouco viril.

Acompanhar o adoecimento de homens mediante referenciais que subvertem a masculinidade hegemônica é uma tarefa difícil, pois nem os trabalhadores acometidos, nem tampouco os profissionais de saúde estão preparados para encarar o adoecimento numa perspectiva de gênero. Prestar uma assistência que não reproduza as imposições da dominação masculina, mas que problematize as questões de gênero, buscando desconstruir a oposição de masculino e feminino 6 como positivo $\mathrm{x}$ negativo, pode ajudar os homens a reelaborar sua existência com base nas mais diversas possibilidades de masculinidades existentes.

Riessman 36 destaca um aspecto a ser explorado nas práticas de cuidado com a saúde dos homens: o fato de que homens de diferentes classes sociais vão vivenciar o adoecimento e observar impactos em sua masculinidade de distintas formas. A autora destaca ainda que a falta de "capital social" influencia o fortalecimento da experiência de finitude da vida, o que leva a doença a manter esses sujeitos presos à ideia de que não há solução para sua existência.

Por fim, no horizonte de Hugo e de alguns trabalhadores investigados estava o desejo de retornar à fábrica, abrir o próprio negócio ou seguir uma carreira estável no serviço público, num início de esboço de planos para o futuro: 
"Essa demissão talvez tenha sido até bom para mim. Não sei o que vai ser daqui para adiante. Estou com vontade de fazer uma coisa que eu mesmo me vire para mim mesmo..." (Luiz).

Para Charmaz 28 (p. 276) a passagem da compreensão da doença como inimigo ou como intrusa para uma abordagem dessa experiência como possibilidade de reconstrução pode permitir "reavaliar, redirecionar e reconstruir o Ser". Desse modo, uma abordagem que auxilie os indivíduos a (re)significar o vivenciado pode ser fundamental para auxiliá-los a gerenciar o autocuidado e reorganizar os planos para a vida com um novo projeto.

\section{Considerações finais}

A aproximação por meio das narrativas de homens metalúrgicos com LER/DORT logrou iluminar elementos da dinâmica entre a construção da identidade de trabalhador metalúrgico, a desconstrução do mundo da vida 37 após o adoecimento e a incapacidade prolongada e a ressignificação da identidade masculina hegemônica, com o registro de novas possibilidades para o devir enquanto homem com doença crônica.

Para além do corpo, da autoimagem, da capacidade e do desempenho, há a interdição do futuro. Corroborando com Good ${ }^{37}$, quando o futuro não pode ser projetado, a percepção da vulnerabilidade e da finitude se presentificam em cada cena da vida cotidiana, esses homens passam a viver um "presente contínuo", "sobrecarregado de dor", perdas e exclusão social.

O estudo nos permitiu compreender o processo de adoecimento crônico em homens e, particularmente, os dilemas colocados na perspectiva dos homens e suas masculinidades. A resistência em falar sobre o adoecimento, relatar sintomas, buscar atendimento está relacionada com a necessidade de não se mostrar frágil. A masculinidade hegemônica expõe os homens a mais riscos em saúde, dado que muitas vezes é preciso não dizer para demonstrar a coragem frente aos problemas e perigos da vida.

Masculinidade cumpre papel mediador do adoecimento no trabalho, altera trajetórias de cuidado e explica a dificuldade dos homens na procura de ajuda. Esses resultados reforçam a necessidade de abordar a saúde dos trabalhadores numa perspectiva que combine categorias analíticas como gênero, classe e condições de trabalho. A combinação dessas categorias explicitou neste estudo problemáticas que os estudos clássicos sobre condições de trabalho não costumam privilegiar, dialogando, portanto, com os achados de Brito 8 .

Ao explicitar que padrões de gênero influenciam a produção de condições de saúde entre homens e mulheres de forma diferenciada e também a produção de dados sobre as condições de saúde, recomenda-se detida observação das relações de gênero e saúde nos processos produtivos quando das investigações sobre a saúde dos trabalhadores. Esse caminho pode contribuir para a desconstrução de uma ideia do senso comum, bastante difundida no mundo do trabalho, de que as mulheres adoecem mais por uma suposta fragilidade. Este estudo contribui na explicitação de que homens e mulheres adoecem de forma diferente porque as questões de gênero medeiam a produção de saúde de forma diferenciada.

Tomando esses elementos, acredita-se que é possível uma abordagem de saúde do homem para além da saúde sexual e reprodutiva, compreendendo que a saúde dos homens é produzida por múltiplos determinantes e condicionantes, sendo o trabalho, os modelos de masculinidades e as formas como os homens experimentam e significam o adoecimento importantes fatores a serem levados em conta na formulação de políticas de promoção da saúde e cuidados em saúde para a população masculina.

Ao se operar o conceito de masculinidades nas políticas de saúde, é necessário também reconhecer que homens em faixas etárias, classes econômicas, raça-etnia, entre outras características diferenciadoras, requerem abordagens diferenciadas para as suas necessidades de saúde 38 , o que constitui mais um desafio para a saúde coletiva. 


\section{Colaboradores}

J. H. S. Saldanha participou da concepção do projeto que gerou o artigo, análise e interpretação dos dados, redação do artigo e aprovou a versão final a ser publicada. M. A. G. Lima conduziu a revisão crítica do conteúdo intelectual e aprovou a versão a ser publicada. R. F. Neves e J. A. B. Iriart participaram da redação do artigo, fizeram a revisão crítica do conteúdo intelectual e aprovaram a versão final a ser publicada.

\section{Agradecimentos}

À Coordenação de Aperfeiçoamento de Pessoal de Nível Superior (Capes) pelo financiamento da pesquisa com bolsa de pós-graduação.

\section{Referências}

1. Chiavegatto Filho LG, Pereira Jr. A. LER/ DORT: multifatorialidade etiológica e modelos explicativos. Interface Comun Saúde Educ 2004; 8:149-62.

2. Salim CA. Doença do trabalho - exclusão, segregação e relações de gênero. São Paulo Perspect 2003; 17:11-24.

3. Neves MY, Brito J, Araújo AJS, Siva EF. Relações sociais de gênero e divisão sexual do trabalho: uma convocação teórico-analítica para estudos sobre a saúde das trabalhadoras da educação. In: Minayo C, Machado JMH, Pena PGL, organizadores. Saúde do trabalhador na sociedade brasileira contemporânea. Rio de Janeiro: Editora Fiocruz; 2011. p. 495-516.

4. Brito J. Trabalho e saúde coletiva: o ponto de vista da atividade e das relações de gênero. Ciênc Saúde Coletiva 2005; 10:879-90.

5. Scott JW. Gênero: uma categoria útil de análise histórica. Educação \& Realidade 1995; 20:7199.

6. Bourdieu P. A dominação masculina. Rio de Janeiro: Bertrand Brasil; 2002.

7. Brito JC. Saúde, trabalho e modos sexuados de viver. Rio de Janeiro: Editora Fiocruz; 1999.

8. Brito JC. Enfoque de gênero e relação saúde/ trabalho no contexto de reestruturação produtiva e precarização do trabalho. Cad Saúde Pública 2000; 16:195-204.

9. Hirata H. Division sexuelle et internationale du travail. Futur Antérieur 1993; 16:27-40.

10. Minayo-Gomez C, Thedim-Costa SMF. Incorporação das ciências sociais na produção de conhecimentos sobre trabalho e saúde. Ciênc Saúde Coletiva 2003; 8:125-36.

11. Belo RP, Camino L. Trabalho e gênero: elaborações discursivas sobre os papéis profissionais. Cad Psicol Soc Trab 2012; 15:271-86.

12. Bruschini MCA, Ricoldi AM. Revendo estereótipos: o papel dos homens no trabalho doméstico. Revista Estudos Feministas 2012; 20:259-87.

13. Souza EM, Bianco MF, Junquilho GS. Contestações sobre o masculino no contexto do trabalho: estudo pós-modernista em mineradoras e siderurgias. Revista de Administração Contemporânea 2015; 19:269-87.

14. Siqueira MJT. A constituição da identidade masculina: alguns pontos para discussão. Psicol USP 1997; 8:113-30. 
15. Gomes R, Schraiber LB, Couto MT. O homem como foco da saúde pública. Ciênc Saúde Coletiva 2005; 10:4.

16. Alves PC. A experiência da enfermidade: considerações teóricas. Cad Saúde Pública 1993; 9:263-71.

17. Connell R. Masculinities. Berkeley: University of California Press; 2005.

18. Connell R. Gender and power: society, the person and sexual politics. Sydney: Allen \&Unwin/Cambridge: Polity Press/Stanford: Stanford University Press; 1987.

19. Connell R, Messerschmidt J. Masculinidade hegemônica: repensando o conceito. Revista Estudos Feministas 2013; 21:241-2.

20. Kimmel MS. A produção simultânea de masculinidades. Horizontes Antropológicos 1998; 4:103-17.

21. Rabelo MCM, Alves PCB, Souza IMA. Experiência de doença e narrativa. Rio de Janeiro: Editora Fiocruz; 1999.

22. Jovchelovitch S, Bauer MW. Entrevista narrativa. In: Bauer MW, Gaskell G, organizadores. Pesquisa qualitativa com texto imagem e som. Petrópolis: Editora Vozes; 2002. p. 90-113.

23. Minayo MCS. O desafio do conhecimento: pesquisa qualitativa em saúde. São Paulo: Editora Hucitec; 2012.

24. Bury M. Illness narratives: factor fiction? Sociol Health Illn 2001; 23:263-85.

25. Sarti CA. A família como ordem moral. Cad Pesqui 1994; (91):46-53.

26. Boltanski L. As classes sociais e o corpo. Rio de Janeiro: Edições Graal; 1989.

27. Walter N, Bourgois P, Loinaz HM. Masculinity and undocumented labor migration: injured Latino day laborers in San Francisco. Soc Sci Med 2004; 59:1159-68.

28. Charmaz K. Identity dilemmas of chronically ill men. In: Sabo DF, Gordon DF, editors. Men's health and illness: gender, power, and the body. Thousand Oaks: Sage Publications; 1995. p. 266-91.
29. Saldanha JHS. Sonhos interrompidos: trajetórias de incapacitação em homens metalúrgicos portadores de LER/DORT [Dissertação de Mestrado]. Salvador: Universidade Federal da Bahia; 2013.

30. Gibson BE, Young NL, Upshur RE, McKeever P. Men on the margin: a Bourdieusian examination of living into adulthood with muscular dystrophy. Soc Sci Med 2007; 65:505-17.

31. Smith B, Sparkes A. Men, sport, spinal cord injury, and narratives of hope. Soc Sci Med 2005; 61:1095-105.

32. Lyra J. Paternidade adolescente: da investigação à intervenção. In: Arilha M, Ridenti Medrado B, organizadores. Homens e masculinidades: outras palavras. São Paulo: Editora Ecos; 1998. p. 185-214.

33. Whitehead M. The concepts and principles of equity in health. Int J Health Serv 1992; 22:429-45.

34. Medrado B. Homens na arena do cuidado infantil: imagens veiculadas pela mídia. In: Arilha M, Ridenti Medrado B, organizadores. Homens e masculinidades: outras palavras. São Paulo: Editora Ecos; 1998. p. 145-61.

35. Neves RF, Nunes MO. Da legitimação a (res) significação: o itinerário terapêutico de trabalhadores com LER/DORT. Ciênc Saúde Coletiva 2010; 15:211-20.

36. Riessman CK. Performing identities in illness narrative: masculinity and multiple sclerosis. Qual Res 2003; 3:5-33.

37. Good BJ. Medicine, rationality, and experience: An antropological perspective. Cambridge: Cambridge University Press; 1994.

38. Gomes RA. Saúde do homem em foco. São Paulo: Editora Unesp; 2010. 


\section{Abstract}

This study aimed to reveal how metalworkers experience prolonged incapacity for work due to repetitive strain injury/work-related musculoskeletal disorder (RSI/WRMD) and the impact of chronic illness on the construction/deconstruction of masculinity. A qualitative study was performed, based on narrative interviews with male metalworkers in an automotive factory in the State of Bahia, Brazil. The results showed how the conflict in the experience of illness, the maintenance of male identity, and expectations of meeting the rules dictated by hegemonic masculinity are experienced and signified in daily life. Metalworkers' experience of illness with RSI/WRMD is expressed in their incapacity for work, deconstruction of self-esteem, loss of collective identity, and interruption of future prospects. In conclusion, hegemonic masculinity exposes men to more health risks, plays a mediating role in work-related illness, alters trajectories of care, and explains men's unwillingness to seek help.

Cumulative Trauma Disorders; Gender Identity; Masculinity; Occupational Health;

Qualitative Research

\section{Resumen}

El objetivo de este estudio fue comprender cómo viven la incapacidad prolongada para el trabajo, debido a lesiones por esfuerzos repetitivos y trastornos osteo muscular relacionados con el trabajo (LER/DORT), los trabajadores metalúrgicos, así como su impacto en el padecimiento crónico y en la construcción/deconstrucción de la masculinidad. Se realizó un estudio cualitativo, basado en entrevistas narrativas con hombres del sector metalúrgico de un complejo automovilístico en el estado de Bahía, Brasil. Los resultados revelaron cómo el conflicto de la experiencia del padecimiento, el mantenimiento de su identidad masculina, así como las expectativas de cumplir las reglas dictadas por la masculinidad hegemónica se viven y se manifiestan en el día a día. La experiencia de padecimiento de los trabajadores metalúrgicos con $L E R / D O R T$ se expresa en la incapacitación para el trabajo, deconstrucción de la autoimagen, pérdida de la identidad colectiva, deconstrucción del self y la ausencia de perspectivas de futuro. Se concluye que la masculinidad hegemónica expone a los hombres a más riesgos en salud, cumple un papel mediador de la enfermedad en el trabajo, altera trayectorias de cuidado y explica la resistencia de los hombres a buscar ayuda.

Trastornos de Traumas Acumulados; Identidad de Género; Masculinidad; Salud Laboral; Investigación Cualitativa
Recebido em 07/Dez/2016

Versão final reapresentada em 17/Out/2017 Aprovado em 16/Nov/2017 